\title{
Health And Convergence Of Health Care Expenditure In EU
}

Kaie Kerem, (Email: kkerem@tv.ttu.ee), Tallinn University of Technology, Estonia Tiia Püss, (Email: tiia.pyss@tv.ttu.ee), Tallinn University of Technology, Estonia Mare Viies, (Email: mare.viies@tv.ttu.ee), Tallinn University of Technology, Estonia Reet Maldre, (Email: reet.maldre@tv.ttu.ee), Tallinn University of Technology, Estonia

\begin{abstract}
The objective of the paper is to review and analyze the health of population and health care expenditure and to examine the trends of convergence of health care expenditure in EU countries. One of the most often used indicators characterizing a population's health is life expectancy at birth. Comparative analyses show that the life expectancy at birth in EU-12 countries is much lower than in EU-15 countries. Although in 1992-2004 the life expectancy increased both in EU15 countries and in EU-12 countries, the differences in the life expectancy have still remained more or less the same. Besides the low life expectancy in EU-12 countries, also the resources used in health care are below the EU-15 average level. In our paper we test the $\beta$-, $\sigma$ - and $\gamma$ convergence of the health care expenditure. For testing $\beta$-, $\sigma$ - and $\gamma$-convergence the authors have used cross-sectional data over the period 1992-2004 for health care expenditure as share of GDP and per capita health care expenditure. Data of the World Health Organization (WHO) were used for the research. The study demonstrates that although usually the increase of economic integration facilitates economic growth, the mere fact of the European Union enlargement does not bring along an automatic homogenization of health care expenditure and health policy in the EU-12 countries.
\end{abstract}

\section{INTRODUCTION}

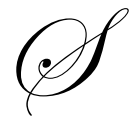

everal economic growth theories treat human capital as the principal factor of economic growth. The quality of human capital depends not only on the educational level of population, but also on health. The population's health situation is affected by various social and economic factors, but also by health policy and the resources used in health care. Macroeconomic evidence confirms that countries with the weakest conditions of health and education have much harder time achieving a sustained growth than countries with better conditions of health and education (Macroeconomics and Health, 2001). The state of health of the employees has an equally important role. The better health may increase output not only through labor productivity but also through the accumulation of capital (see Bils and Klenow, 2000; Bloom et al., 2001). Analyses of the inter-relationships between health and economic productivity can be conducted at the level of individuals, at regional levels within a country, and for aggregate data on countries (Bhargava et al., 2001). There are numerous studies on the relationship between health and economic growth (see, for example, Alsan et al., 2006; Jamison et al., 2004; Bloom et al., 2003; Macroeconomics and Health, 2001; Kalemi-Ozcan et al., 2000; etc.).

Bloom, Canning and Sevilla (2001) added into their model of economic growth in addition to other parameters also average life expectancy and found that health has a positive and statistically significant effect on economic growth. "It suggests that one-year improvement in life expectancy contributes to an increase of 4 percent in output. This is a relatively large effect indicating that increased expenditures improving health might be justified purely on the ground of their impact on labor productivity" (ibid, p. 20). Bhargava, Jamison and Murray (2001) found that the 5-year growth rate of per capita GDP depends among other factors also on the mortality rate of adults. Alsan, Bloom Canning (2006) discovered that a one-year improvement in life expectancy is associated with an 9\% increase in gross FDI inflow to low- and middle-income countries. 
Campos and Coricelli (2002) have analyzed the economic growth of transition economies and showed that the early years of the transition witnessed a rapid increase in mortality rates, and a major explanatory factor for these is the increase in adult male mortality (Campos and Coricelli, 2002). According to Sala-i-Martin, Doppelhofer and Miller (2004), human capital and health (life expectancy) are one of the main factors of long-term economic growth.

A substantial part of the literature is examining the convergence across countries over time (Barro, 1991; Mankiw et al., 1992; Barro and Sala-i-Martin, 1992; Sala-i-Martin, 1996, DeLong, 1988, etc.). Also, there have been a large number of studies confirming the importance of human capital. Several studies have presented evidence of the convergence, using measures of education (O'Neill, 1995; Cohen, 1996). Nixon (1999) analyzed the health care expenditures in EU countries and found that health care expenditures are converging upwards towards the EU mean. Sab and Smith (2001) analyzed human capital convergence, using the enrollment rates and life expectancy. According to their paper, "the improvement in health is more critical to successful improvement in education, than is the improvement of education to successful improvement in health" (ibid, p.21).

The rest of the paper is structured as follows. In section 2, we analyze health care expenditure as per cent of GDP and per capita health care expenditure in EU-15 and in EU-12 member states. Section 3 describes the theoretical approaches of the evaluation methods of convergence used in this research. Section 4 shows empirical results of convergence in health care expenditure and the last section concludes the paper. We have used the WHO database. The sample covers the period of 1992-2004. The countries under study are EU member states included EU new member states for which the data are available (Czech Republic, Estonia, Hungary, Latvia, Lithuania, Poland, Slovakia, Slovenia).

\section{HEALTH AND HEALTH CARE EXPENDITURE: COMPARATIVE ANALYSIS}

Among the indicators characterizing a population's health, one of the most often used ones internationally is life expectancy at birth. Comparing the life expectancy at birth in EU-12 countries and in EU-15 countries we can see that in EU-15 the life expectancy at birth is higher than in EU-12 countries (see Figure 1).

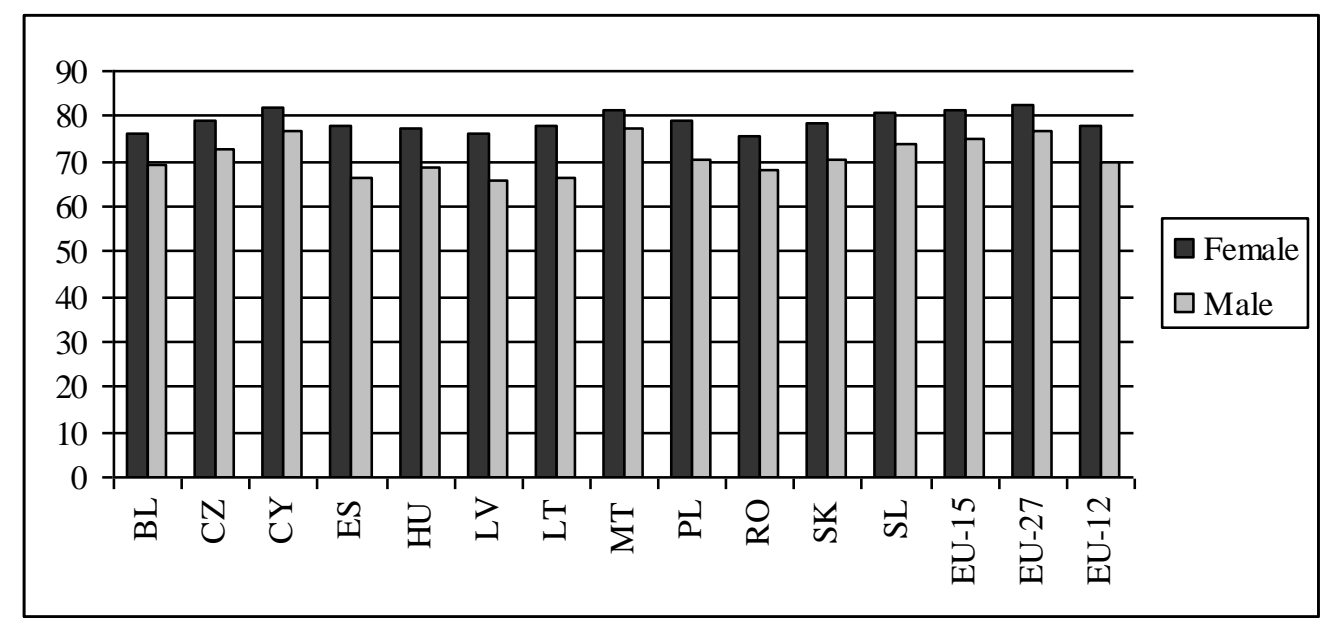

Figure 1: Females and males life expectancy at birth in 2004

Although in 1991-2004 the life expectancy rose both in EU-15 countries and EU-12 countries, the differences in the life expectancy have still remained more or less the same. The life expectancy in EU-15 was 75.29 years in 1991 and 78.27 in 2004; the respective indices in EU-12 were 70.73 and 73.91. 
If to compare the Baltic states to EU-15, we can see that the life expectancy in the Baltic states is lower. Sharp economic changes in the Baltic states caused an essential decline in the life expectancy in the transition period. Figure 2 demonstrates that the life expectancy fall that started in 1991 achieved its lowest in 1994, whereas the in Estonia and Latvia the decline was bigger than in Lithuania. By 1997, the Baltic states achieved the life expectancy level that was before the beginning of the decline. From then on the life expectancy has been rising and the difference from EU-15 has diminished slightly (see Figure 2)

The difference between male and female life expectancy in EU-15 countries was approximately 6 years in 2004, but in EU-12 countries it was much bigger (approximately 10 years)(see Figure 1). This difference is especially large in Estonia and Lithuania (approximately 11 years). The male life expectancy in the Baltic states is approximately 10 years shorter than in the average for EU- 15 .

Life expectancy has increased in all EU Member States excluding Baltic countries. For example, in Estonia the life expectancy has increased 2.88 years for men and 3.24 years for women over the same period (WHO database). The only exception is Latvia where the male life expectancy rose only 0.25 years over the period 19912004. As noted before, life expectancy in the Baltic countries is especially low among men. A problem in the Baltic countries is early mortality - that is deaths before 65 years of age, which make up nearly one third of all deaths. The major explanatory factor is psychological stress associated with turbulent times, with rising unemployment, poverty, and alcohol consumption (Brainerd et al.1998).

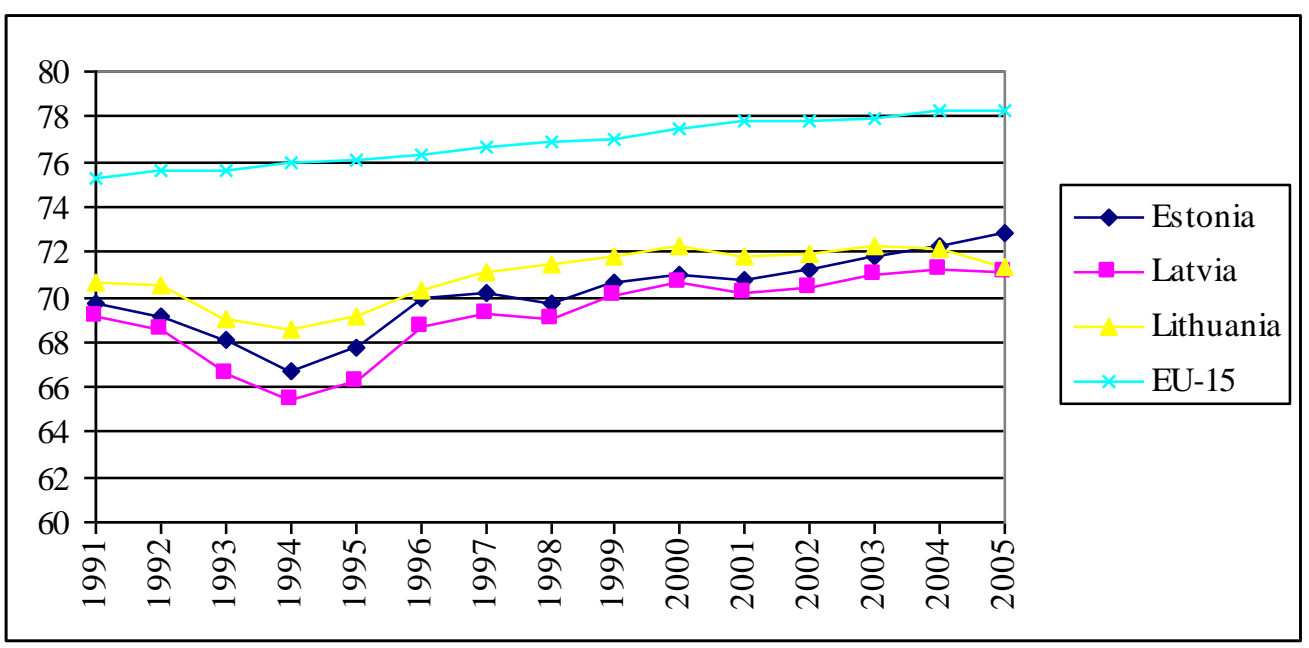

Figure 2: Life expectancy at birth in Baltic countries and in EU-15 in 1991-2005

Besides the low life expectancy in EU new member states, also the resources used in health care sector are below the EU average level. In 2004, the average EU-15 expenditure on health care was 9.43\% of the GDP, which are approximately 3 percentage points higher than in EU-10 (see Table 1). 
Table 1: Total health care expenditure as percentage of GDP and PPP\$ per capita

\begin{tabular}{|c|c|c|c|c|c|c|c|}
\hline \multirow{2}{*}{$\begin{array}{c}\text { Country } \\
\text { Relative order based } \\
\text { on data of } 2004\end{array}$} & \multicolumn{3}{|c|}{$\begin{array}{l}\text { Total health care expenditure as \% } \\
\text { of GDP }\end{array}$} & \multirow{2}{*}{\begin{tabular}{|c|} 
Country \\
Relative order \\
based on data of \\
2004 \\
\end{tabular}} & \multicolumn{3}{|c|}{$\begin{array}{c}\text { Total health care expenditure, PPP\$ } \\
\text { per capita }\end{array}$} \\
\hline & 1992 & 2004 & $\begin{array}{c}\text { Change } \\
\text { 1992-2004 } \\
\text { (\% points) } \\
\end{array}$ & & 1992 & 2004 & $\begin{array}{c}\text { Change } \\
\text { 1992s }(\%)\end{array}$ \\
\hline Germany & 9.7 & 10.7 & 1.0 & Luxembourg & 1758 & 5089 & 289.5 \\
\hline France & 8.9 & 10.5 & 1.6 & France & 1752 & 3159 & 180.3 \\
\hline Portugal & 7 & 10 & 3.0 & Belgium & 1557 & 3145 & 201.9 \\
\hline Greece & 7.9 & 9.8 & 1.9 & Austria & 1541 & 3124 & 202.7 \\
\hline Belgium & 7.7 & 9.8 & 2.1 & Germany & 1961 & 3056 & 155.8 \\
\hline Austria & 7.4 & 9.6 & 2.2 & Netherlands & 1632 & 3041 & 186.3 \\
\hline Sweden & 8.3 & 9.3 & 1.0 & Denmark & 1641 & 2881 & 175.6 \\
\hline Denmark & 8.3 & 8.9 & 1.6 & Sweden & 1604 & 2825 & 176.1 \\
\hline Netherlands & 8.1 & 8.9 & 0.8 & Ireland & 1007 & 2596 & 257.8 \\
\hline Italy & 8 & 8.7 & 0.7 & United Kingdom & 1181 & 2546 & 215.6 \\
\hline Slovenia & 7.4 & 8.6 & 1.2 & Italy & 1550 & 2392 & 154.3 \\
\hline United Kingdom & 6.9 & 8.3 & 1.4 & Finland & 1552 & 2235 & 144.0 \\
\hline Hungary & 7.6 & 8.3 & 0.7 & Greece & 963 & 2162 & 224.5 \\
\hline Spain & 7.1 & 8.1 & 1.0 & Spain & 1030 & 2094 & 203.3 \\
\hline Luxemburg & 5.4 & 7.7 & 2.2 & Portugal & 852 & 1813 & 212.8 \\
\hline Finland & 9 & 7.5 & -1.5 & Slovenia & 448.5 & 1801 & 401.6 \\
\hline Czech Republic & 5.1 & 7.3 & 2.2 & Czech Republic & 570 & 1361 & 238.8 \\
\hline Ireland & 7 & 7.1 & 0.1 & Hungary & 633 & 1323 & 209.0 \\
\hline Poland & 6.2 & 6.5 & 0.3 & Poland & 378 & 805 & 213.0 \\
\hline Cyprus & 4.6 & 6.3 & 1.7 & Lithuania & 155.4 & 786.4 & 506.0 \\
\hline Latvia & 2.8 & 6.3 & 3.5 & Estonia & 301.1 & 771.4 & 256.2 \\
\hline Lithuania & 4.2 & 6 & 1.8 & Latvia & 169.7 & 734.1 & 432.6 \\
\hline Estonia & 4.5 & 5.3 & 0.8 & EU-12 & 353.7 & 782.8 & 221.3 \\
\hline EU-12 & 5.32 & 6.01 & 0.69 & EU-15 & 1524 & 2694 & 176.8 \\
\hline EU-15 & 8.21 & 9.43 & 1.22 & & & & \\
\hline
\end{tabular}

Source: WHO database

The corresponding ratio at the same time was more than 3 percentage points lower in Latvia and in Lithuania. The ratio was the lowest in Estonia (5.3\%), which positioned Estonia the last, among 23 countries (see Table 1). From the new member states in Slovenia the health care expenditure as percentage of GDP comes closest to the EU-15 average. The highest health care expenditure in 2004 was in Germany (10.7\% of GDP).

Despite that the share of health care expenditure in GDP in the period 1992-2004 increased in all EU member states (with the exception of Finland), the growth in EU old member states was faster than in new member states (Figure 3). 


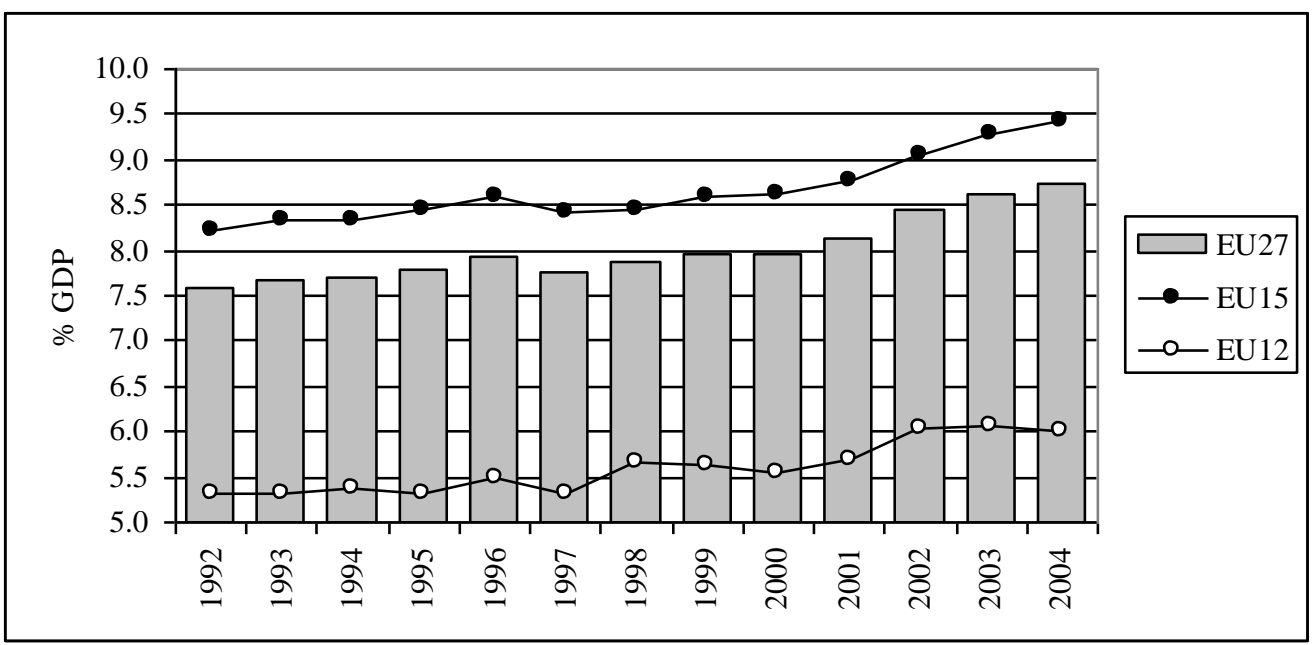

Figure 3: Health care expenditure as share of GDP

The per capita health care expenditure in EU-15, on average (based on PPP\$), was $1524 \$$ in 1992 and $2694 \$$ in 2004. During the period 1992-2004, the per capita health care expenditure increased in all of the EU countries (see Figure 4). Figure 4 depicts that per capita health care expenditure in the period 1992-2004 increased in EU-15 much faster than in EU-12.

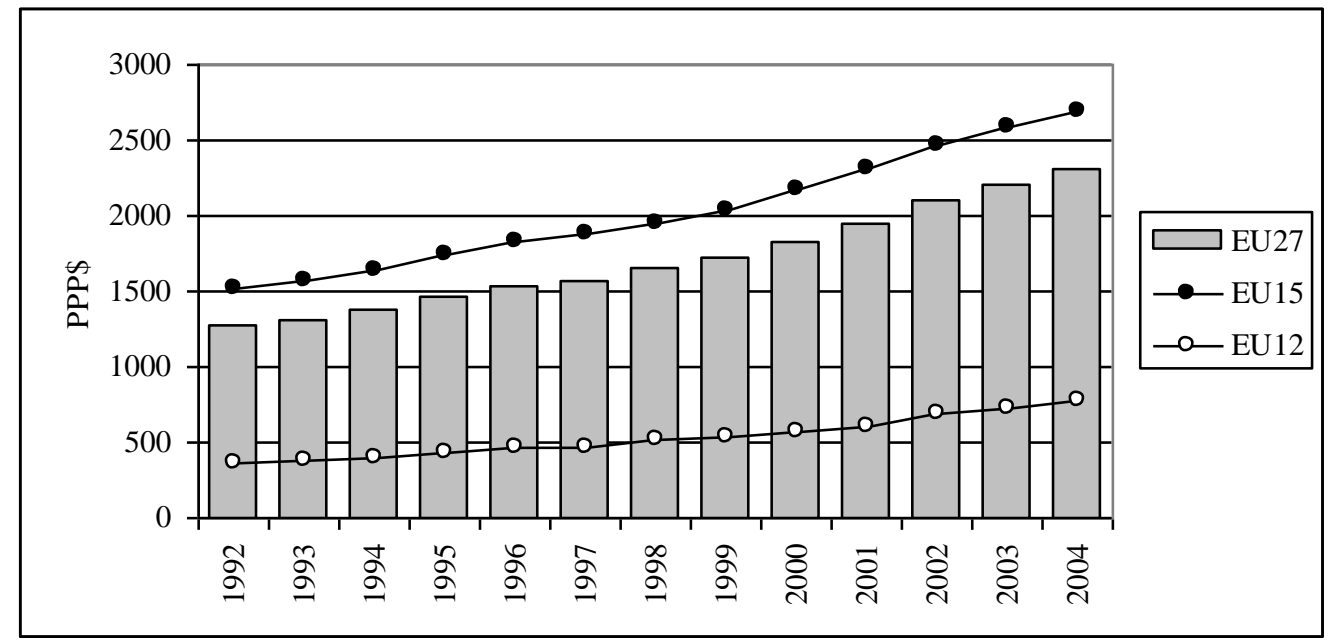

Figure 4: Per capita health care expenditure

The biggest growth of per capita health care expenditure in the period 1992-2004 was in Latvia, the smallest in Finland (see Table 1). Comparing the shares of health care expenditure in GDP and health care expenditure per capita, we can see that the relative order of countries based on data of 2004 has changed. The first position by the share of health care expenditure in GDP was occupied by Germany, but Luxembourg had the leading position by per capita health care expenditure. At the same time, the Baltic states close the ranking lists in both indicators. 
The highest per capita health care expenditure was in Luxembourg - 189\% of the EU-15 average in 2004 . Among the new member states, Slovenia had the biggest per capita health care expenditure $-67 \%$ of the average EU-15 level (see Figure 5)

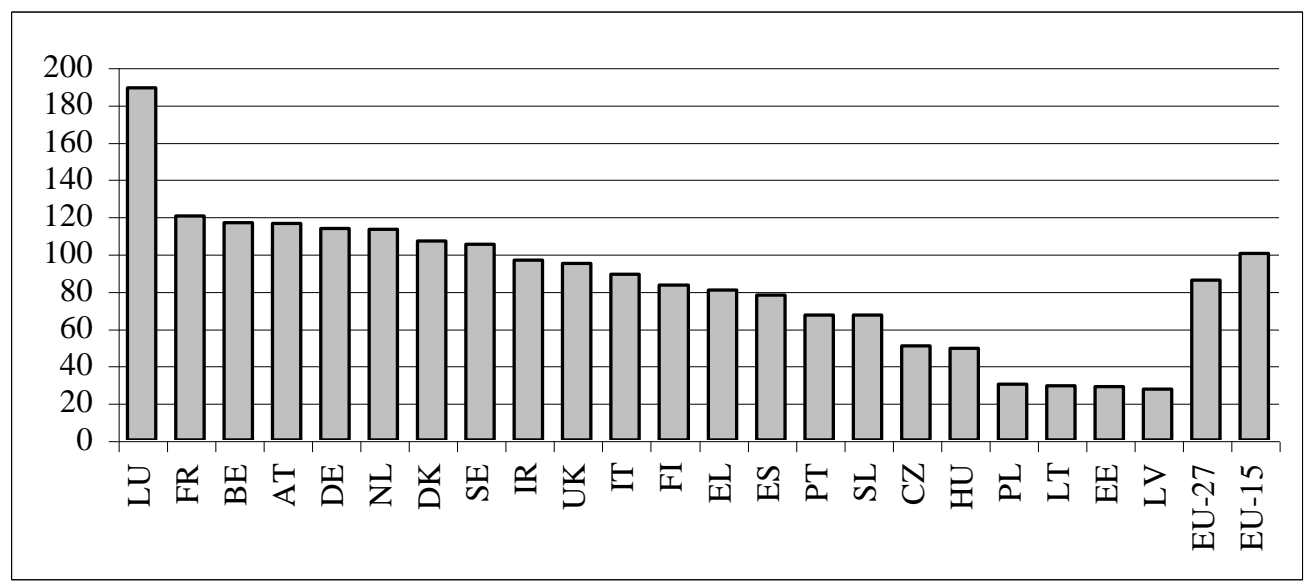

Figure 5: Health care expenditure in 2004 in \% compared to EU-15 (EU-15 =100)

At the same time, per capita health care expenditure in Estonia was $28.6 \%$, in Latvia $27 \%$ and Lithuania $29 \%$ of the EU-15 average level. The above analysis demonstrated that life expectancy in EU new member states is much lower than in old ones. The situation of health care expenditure is similar, both per capita expenditure and as percentage of GDP.

\section{METHODS FOR EVALUATING CONVERGENCE}

According to the economic theory of convergence, economic development level of less developed countries should approach the level of more advanced countries which have the same economic resources or fundamentals. Socio-economic convergence is mainly discussed in the context and on the basis of two main economic growth theories: neo-classical and endogenous. Two main concepts of convergence are used in the classical literature of growth theory: $\sigma$-convergence $\square$ and $\beta$-convergence $\square$ (Quah, 1996; Sala-i-Martin, 1996).

One of the simplest methods for estimating socio-economic convergence is to calculate $\sigma$-convergence on the basis of standard deviation. With this method it is possible to examine how the dispersion between national income levels (or other indicators) has changed, or how the differences of indicators inside groups of countries are changing compared to the average (Dorwick and Nguyen, 1989; Barro and Sala-i-Martin, 1992). A reduction coefficient of variance (standard deviation/arithmetic mean) of indicators indicates a reduction of the difference, or the presence of $\sigma$-convergence.

The test for the presence of $\beta$-convergence (DeLong, 1988; Barro and Sala-i-Martin, 1991, 1992; Sala-iMartin, 1994; Boyle and McCarthy, 1997) posits that $\beta$-convergence exists if a poor economy tends to grow at a faster rate than a rich one so that the poor country tends to catch up in terms of per capita income or product. The literature makes distinction between absolute (unconditional) and conditional $\beta$-convergence. Absolute $\beta$ convergence pertains to the coefficient $\beta$ of the bivariate equation. This is based on the assumption that all countries in the sample converge to the same steady state. 


$$
\begin{aligned}
& \text { We used the following equation to estimate absolute } \beta \text {-convergence: } \\
& \frac{1}{T} \ln \left(\frac{Y_{i T}}{Y_{i 0}}\right)=\alpha+\beta \ln Y_{i 0}+\varepsilon_{i},
\end{aligned}
$$

where the left-hand side is the average annual growth rate of the health care expenditure in country $i$ at time T. $\alpha$ is a constant term, $\varepsilon_{i}$ - the error term. The condition for $\beta$-convergence is the test that $\beta<0$.

For the assessment of the speed of convergence we used the following equation:

$$
\frac{1}{T} \ln \left(\frac{Y_{i T}}{Y_{i 0}}\right)=\alpha-\left(\frac{1-e^{-b T}}{T}\right) \ln Y_{i o}+\varepsilon_{i},
$$

where $b$ is the rate of convergence.

Conditional $\beta$-convergence pertains to the coefficient $\beta$ of the socio-economic level variable in an equation that includes additional explanatory variables reflecting differences across countries, which direct each economy to converge to its own steady state. In both cases, the convergence hypothesis is that the growth rate of a socioeconomic indicator will be negatively related to the level of this indicator.

Boyle and McCarthy proposed a simple but unbiased measure of convergence that is consistent with Sala-iMartin (1994) concept of $\beta$-convergence. Motivation for the measurement is Sala-i-Martin`s (1994) interpretation of $\beta$-convergence, which is concerned with tracking the mobility of individual countries within the distribution of income levels over time. Taking this interpretation as given, a straightforward and direct assessment of intertemporal mobility would require an examination of the change in the ranking of income levels. A simple measure that captures the change in rankings is Kendall's index of rank concordance (Boyle and McCarthy, 1997)

In the context of measuring $\beta$-convergence Kendall's index could be computed in a number of ways. First, one could generate a multi-annual version $\left(R C_{t}\right)$ of the index, which takes account of the ranks for intervening years between $t$ and $O$ by computing the index for a moving-sum of years:

$$
R C_{t}=\frac{\operatorname{Variance} \sum_{t=0}^{T} A R(Y)_{i t}}{\text { Variance }\left((T+1) \times A R\left(Y_{i 0}\right)\right)},
$$

where $A R(Y)_{i t}$ - the actual rank of country $i$ 's income level (per capita) in year $t ; A R(Y)_{i 0}$ - the actual rank of country $i$ 's income level (per capita) in the initial year $0 ; T+1$ - the number of years for which data are used for constructing the index. Alternatively, one could obtain a binary version $\left(R C a_{t}\right)$ by focusing on the concordance between the ranks in year $t$ and year 0 :

$$
R C a_{t}=\frac{\operatorname{Variance}\left(A R(Y)_{i t}+A R(Y)_{i 0}\right)}{\operatorname{Variance}\left(2 \times A R(Y)_{i 0}\right)}
$$

The multi-annual index contains all possible pairs of years for which the binary measure could be computed ( $\gamma$-convergence).

The value of our rank concordance index ranges from zero to unity. The denominator of the index is the maximum sum of ranks, which would be obtained if there were no change in rankings over time. The closer the index value is to zero, the greater the extent of mobility within the distribution. This index is in the spirit of the coefficient of variation measure of $\sigma$-convergence when the latter is converted to a 0.1 index by simply dividing each year's coefficient by the initial year's value. Kendall's original rationale for the rank concordance measure was 
a solution to the problem of ascertaining the overall agreement among $k$ sets of rankings. It is therefore ideally suited to testing for the presence of $\beta$-convergence (Boyle and McCarthy, 1999: p.8).

\section{EMPIRICAL ANALYSIS}

\section{1. $\quad \beta$-convergence}

For testing absolute $\beta$-convergence we used two measures of health care expenditure: health care expenditure as a share of real GDP and per capita health care expenditure at PPP\$. Following Sala-i-Martin (1996), we used a log linear regression to estimate the annual growth rate of the expenditure share based on the initial level of the share at the beginning of the period. If the slope coefficient is negative, we say that there exists absolute convergence in health care expenditure as a share of real GDP and per capita (Tables 2,3).

Regarding absolute $\beta$-convergence, Table 3 shows that the coefficient $\beta$ for health care expenditure as a share of real GDP is negative and statistically significant for EU-23 countries. The value of $\beta$ is -0.040 and $95 \%$ confidence interval $-0.055<\beta<-0.025$. Our results satisfy the conditions for convergence in health care expenditure as a share of real GDP across EU-23 countries and also for EU-8.The value of $\beta$ is -0.054 and $95 \%$ confidence interval $-0.080<\beta<-0.028$ (see Table 2 and Figure 6). As we have verified in our previous studies (Püss et al., 2003), $\beta$-convergence can be identified also in health care expenditure as a share of real GDP across EU-15 countries.

Table 2: Absolute $\beta$-convergence in health care expenditure in 1992-2004, as a share of GDP (\%)

\begin{tabular}{|c|c|c|c|c|c|c|}
\hline & Coef. & StdErr & $\mathbf{T}$ & $\mathbf{P}>\mathbf{t}$ & \multicolumn{2}{|c|}{$[95 \% \mathrm{CI}]$} \\
\hline \multicolumn{7}{|l|}{ EU-23 } \\
\hline $\mathrm{B}$ & -0.040 & 0.008 & -5.250 & 0.000 & -0.055 & -0.025 \\
\hline A & 0.092 & 0.015 & 6.270 & 0.000 & 0.063 & 0.121 \\
\hline $\mathrm{R}^{2}$ & 0.57 & & & & & \\
\hline Annual convergence rate $(\%)$ & 5.5 & 1.7 & 3.1 & 0.005 & 2.1 & 8.9 \\
\hline $\mathrm{T}_{\text {half }}$ (in years) & 13 & 3 & & & 7 & 19 \\
\hline \multicolumn{7}{|l|}{ EU-15 } \\
\hline $\mathrm{B}$ & -0.052 & 0.018 & -2.930 & 0.012 & -0.087 & -0.017 \\
\hline A & 0.119 & 0.037 & 3.260 & 0.006 & 0.048 & 0.191 \\
\hline $\mathrm{R}^{2}$ & 0.40 & & & & & \\
\hline Annual convergence rate $(\%)$ & 8.3 & 3.3 & 2.5 & 0.028 & 1.7 & 14.8 \\
\hline $\mathrm{T}_{\text {half }}($ in years $)$ & 8 & 2 & & & 4 & 13 \\
\hline \multicolumn{7}{|l|}{ EU-8 } \\
\hline $\mathrm{B}$ & -0.054 & 0.013 & -4.124 & 0.006 & -0.080 & -0.028 \\
\hline A & 0.111 & 0.022 & 5.077 & 0.002 & 0.068 & 0.153 \\
\hline $\mathrm{R}^{2}$ & 0.74 & & & & & \\
\hline Annual convergence rate $(\%)$ & 8.7 & 3.5 & 2.5 & 0.049 & 1.8 & 15.7 \\
\hline $\mathrm{T}_{\text {half }}($ in years $)$ & 8 & 2 & & & 3 & 12 \\
\hline
\end{tabular}

Figure 6 demonstrates that there has been $\beta$-convergence in health care expenditure as a share of GDP. The figure displays the convergence hypothesis since a higher initial health care expenditure level is associated with lower growth rate in the level over the period. 


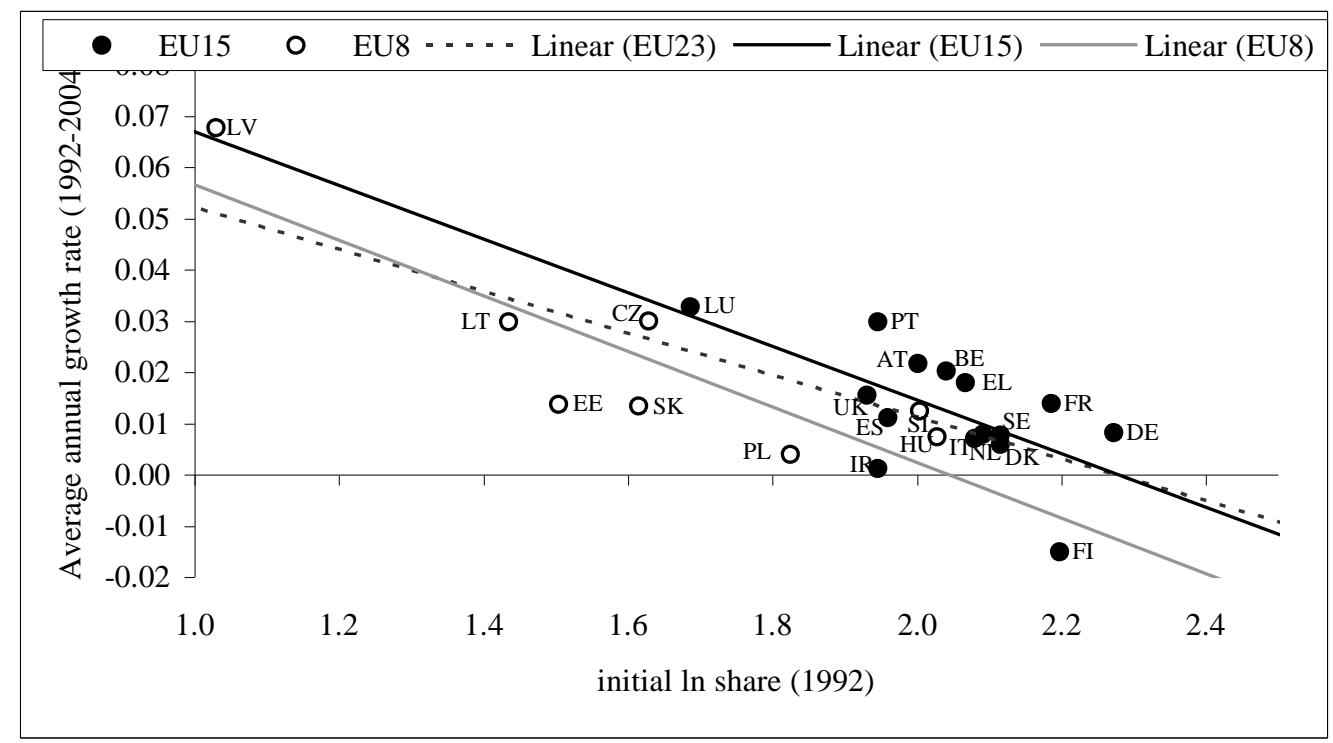

Figure 6: Absolute $\beta$-convergence in health care expenditure in 1992-2004, as a share of GDP (\%)

According to the equation (2), the rate of convergence $(b)$ shows a rather high speed of convergence. The estimated average annual convergence rates are 5.5\% in EU-23, 8.3\% in EU-15 and 8.7\% in EU-8. Starting from 1992, it takes about 10 years for one half of the differences in health care expenditure (as a share in GDP) between EU-8 countries and EU-15 average to disappear at the $7 \%$ annual rate of convergence.

Table 3: Absolute $\beta$-convergence in health care expenditure in 1992-2004, annual growth rate per capita at PPP\$

\begin{tabular}{lcccccc}
\hline & Coef. & StdErr & T & P>t & [95\% CI] \\
\hline EU-23 & & & & & & \\
$\mathrm{B}$ & -0.027 & 0.005 & -5.180 & 0.000 & -0.037 & -0.016 \\
$\mathrm{~A}$ & 0.246 & 0.035 & 7.064 & 0.000 & 0.173 & 0.318 \\
$\mathrm{R}^{2}$ & 0.56 & & & & & \\
$\quad$ Annual convergence rate (\%) & 3.2 & 0.7 & 4.7 & 0.000 & 1.9 & 4.5 \\
$\quad \mathrm{~T}_{\text {half }}$ (in years) & 22 & 4 & & & 14 & 29 \\
\hline $\mathbf{E U}-15$ & & & & & & \\
$\beta$ & -0.027 & 0.015 & -1.790 & 0.097 & -0.600 & 0.006 \\
$\alpha$ & 0.252 & 0.110 & 2.300 & 0.039 & 0.015 & 0.488 \\
$\mathrm{R}^{2}$ & 0.20 & & & & & \\
Annual convergence rate (\%) & 3.3 & 1.8 & 1.8 & 0.1 & -0.3 & 6.9 \\
$\mathrm{~T}_{\text {half }}$ (in years) & 21 & 8 & & & 6 & 36 \\
\hline $\mathbf{E U - 8}$ & & & & & & \\
$\beta$ & -0.047 & 0.017 & -2.850 & 0.029 & -0.088 & -0.007 \\
$\alpha$ & 0.365 & 0.098 & 3.730 & 0.010 & 0.125 & 0.604 \\
$\mathrm{R}^{2}$ & 0.58 & & & & & \\
Annual convergence rate (\%) & 7.0 & 1.6 & 4.3 & 0.000 & 3.8 & 10.2 \\
$\mathrm{~T}_{\text {half }}$ (in years) & 10 & 2 & & & 6 & 14 \\
\hline
\end{tabular}


Table 3 shows that analogously with health care expenditure as a share of GDP the coefficient of $\beta \square$ for per capita health care expenditure was negative and statistically significant for all groups of EU countries in the period 1992-2004. For EU-23 countries are the values: $\beta-0.027$ and $95 \%$ confidence interval $-0.037<\beta<-0.016$. There are two main outliers, Slovenia and Luxembourg, where the initial level of health care expenditure was higher and the growth faster compared with EU-8 and EU-15 countries' average, respectively. Without these two countries the $\beta$ coefficient won't change notably for EU-23, but would have fallen to the level -0.038 in EU-15 and -0.053 in EU-8 and would have been statistically more reliable. The presence of absolute $\beta$-convergence $(\beta<0)$ for all groups of countries indicates dependence of growth on the initial level of the indicator. On the whole, our results satisfy the conditions for convergence in health care expenditure per capita across EU countries over the period 1992-2004.

Figure 7 illustrates the health care expenditure per capita at PPP convergence across EU-23 countries in the period 1992-2004. The initial level is on the horizontal axis and the annual rate of growth on vertical axis. According to the definition of absolute $\beta$-convergence, for convergence to exist the regression line must be downward sloping.

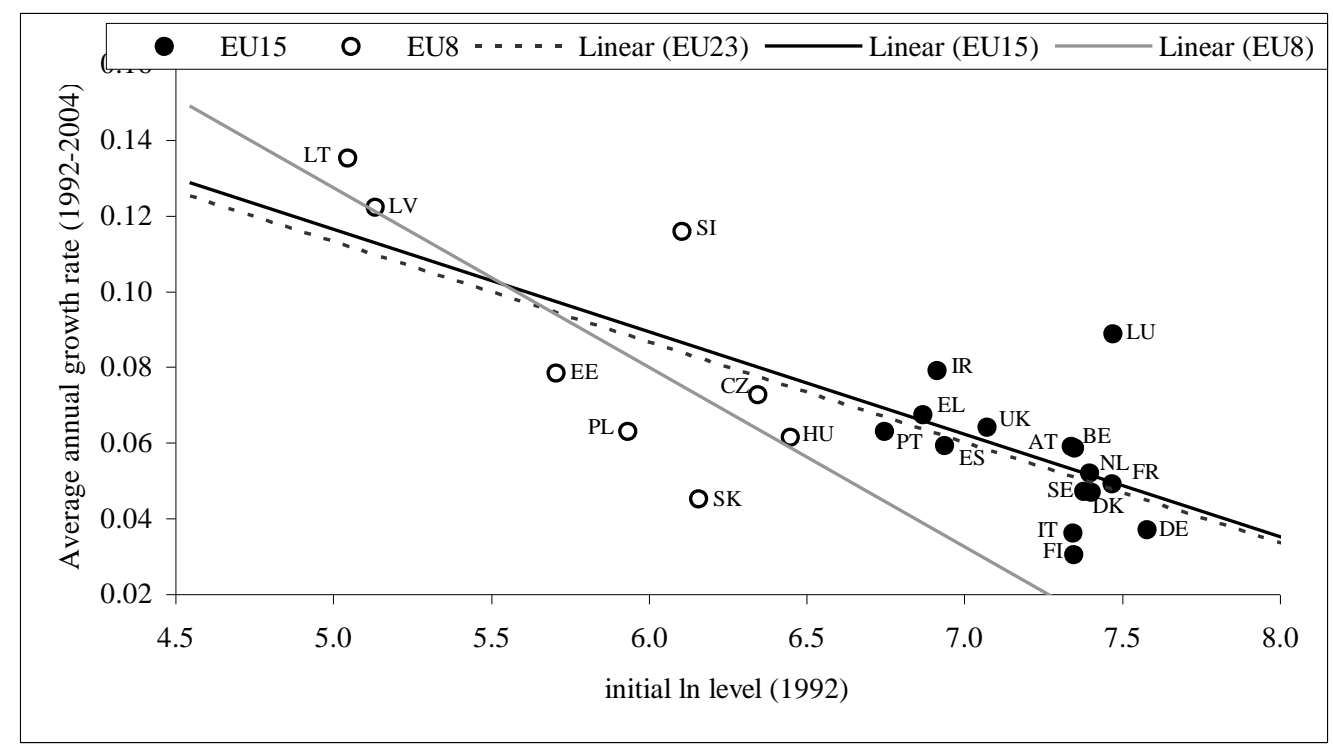

Figure 7: Absolute $\beta$-convergence in health care expenditure in 1992-2004, per capita at PPP\$

\section{2. $\sigma$ - and $\gamma$ - convergence}

We evaluate $\sigma$-convergence in EU-23 countries and independently in EU-15 countries and EU-8 countries, using the total health care expenditure as \% of GDP and per capita at PPP\$. The tested variation coefficient for EU23 countries fell from 0.247 to 0.186 (Figure 8) and from 0.546 to 0.490 (Figure 9) respectively, conforming that the health care expenditures have converged in the period 1992-2004. This is also evidenced by the increased ratio of the minimum to maximum of both indicators: for health care expenditures as \% of GDP from $29 \%$ to $50 \%$ and for health expenditure per capita from $8 \%$ to $14 \%$. The country with the highest health care expenditure per capita at the beginning of the period was Germany, but since 1999 it has been Luxembourg, and its lead before other countries has progressively increased from year to year. The health care expenditure was the lowest throughout the period in Latvia. 


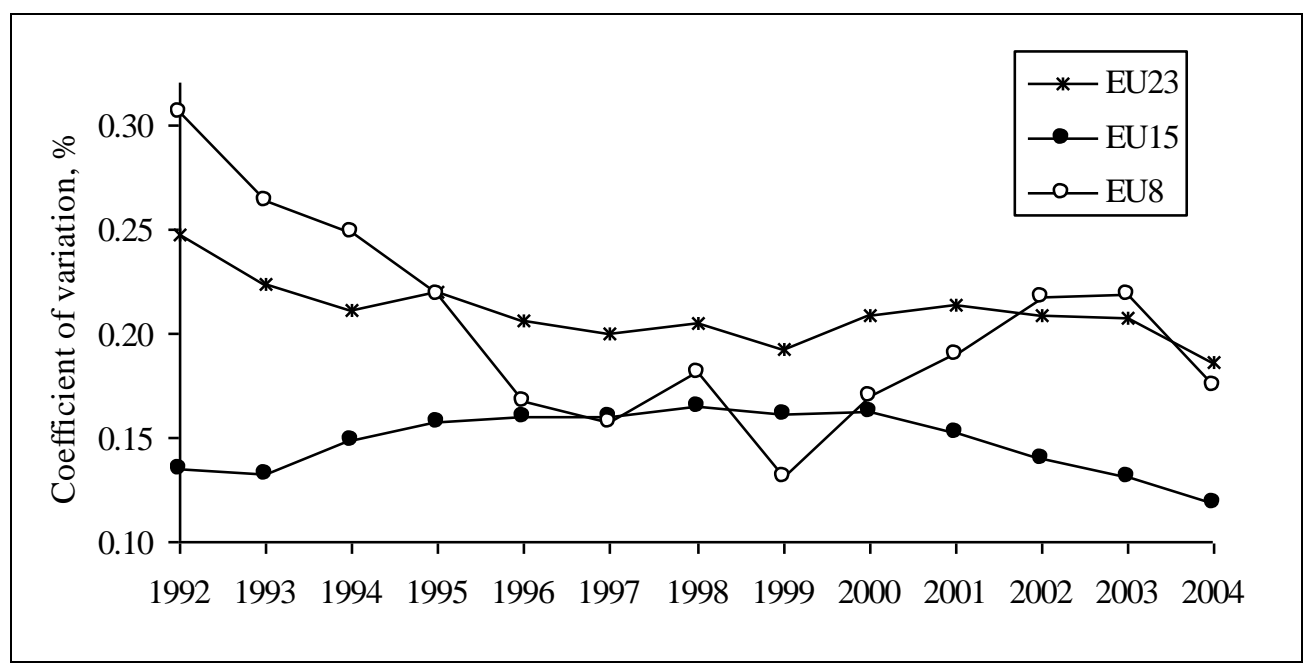

Figure 8: Coefficients of variation of health care expenditure as a share of GDP

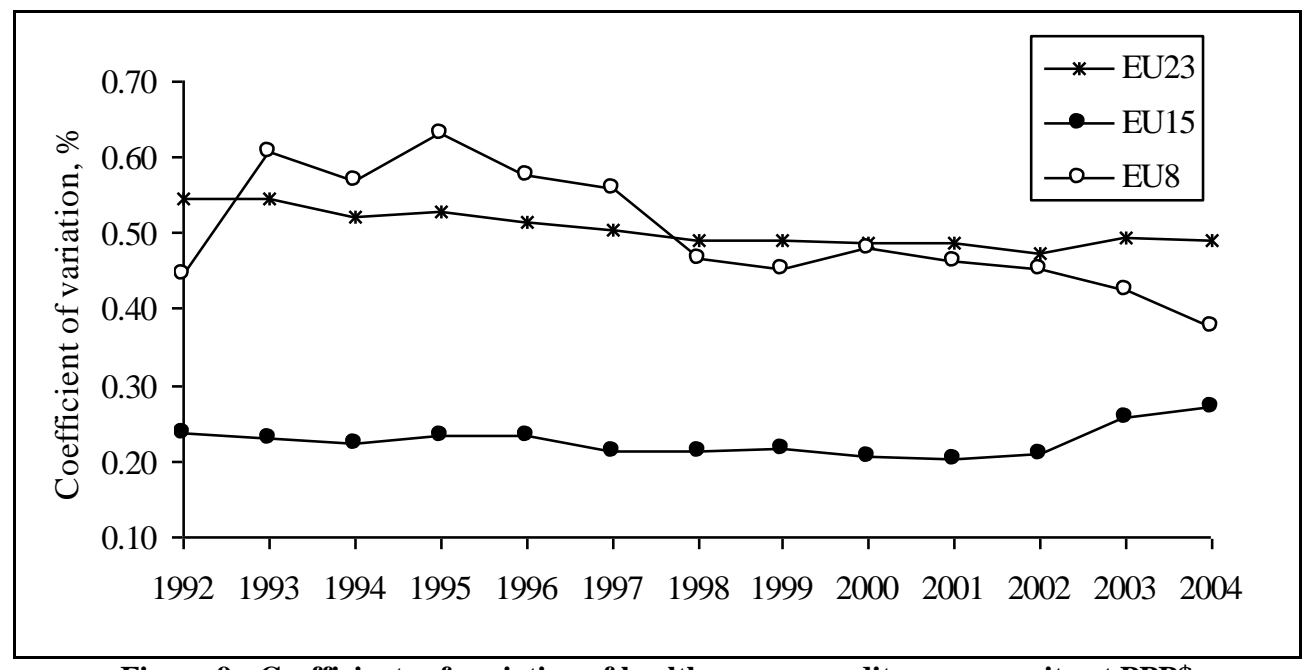

Figure 9: Coefficients of variation of health care expenditure per capita at PPP\$

In EU-15 countries we can observe the divergence of health care expenditure as a share of GDP in the period 1992-2000 (the coefficient of variation increased from 0.134 to 0.163) and convergence in the period 20002004 (the coefficient of variation fell from 0.163 to 0.119) (Figure 8). Exactly the opposite is the situation in health care expenditure per capita. In the period 1992-2001, the variation coefficient fell from 0.236 to 0.202 and in the period 2001-2004 rose from 0.202 to 0.272 (Figure 9). Analyzing the changes in countries we can see that an extraordinarily fast growth of per capita expenditure in Luxembourg is a factor that led to divergence at the end of the period. The increase in the per capita health care expenditure has been induced in addition to a fast economic growth in Luxembourg, where the development level is very high, by an increasing pendulum migration in recent years. According to the health care organization in Luxembourg, all citizens of the neighboring countries who work in Luxembourg (about $25 \%$ of Luxembourg's insured workers) are covered by health insurance, while per capita expenditure calculations are based on the resident population. $\sigma$-convergence calculations without Luxembourg confirm the influence of this country on the presence of divergence in recent years.

In the EU-8 countries the coefficient of variation of per capita health care expenditure decreased from 0.446 in 1992 to 0.377 in 2004. However, the beginning of the period was characterized rather by a divergence, but since 1996 the differences between countries have diminished (increased only in 2000). In health expenditure as a share of 
GDP the variation coefficient decreased until 1999 from 0.306 to 0.131 . From 1999 to 2003 we had a divergence period. In EU-8 countries the ratio of minimum to maximum expenditure has improved, both per capita and as a share of GDP. At the same time, changes have occurred in countries with the minimal and maximal level. Early in the period, the lowest level of the indicators was in Latvia and the highest in Hungary, but by the end of the period Slovenia achieved the maximum level and Estonia had fallen to the minimum level by the share of expenditure in GDP.

As we know from the theory, $\sigma$-convergence is sufficient for $\beta$-convergence. In the periods when $\sigma$ is more or less stable, the $\beta$-convergence exists when substantial $\gamma$-convergence takes place. In addition to testing for $\beta$ convergence, the Kendall's rank concordance index ( $\gamma$-convergence) enables to estimate changes in the country's ranking. A binary indicator measures the importance of changes compared to the base period, while multi-annual index measures changes taken place during the whole test period.

Tables 4-6 present the coefficient of variance that characterizes changes of $\sigma$-convergence compared to the first year of survey (columns 2 and 5). The measures of $\beta$-convergence, based on the multi-annual Kendall's rank concordance index, are presented in columns 3 and 6 and the Binary-Kendall version in columns 4 and 7.

Based on the analysis of $\sigma$-convergence we can affirm that health care expenditures (\% of GDP) in EU-15 have diverged in the period 1992-2000 and converged in the period 2001-2004. Calculated for the whole period, the average speed of $\sigma$ - convergence was $1.04 \%$ per year (Table 4) and the average speed of $\gamma$-convergence, based on Kendall's binary and multi-annual indices, was $2.04 \%$ and $2.16 \%$ per year. There were statistically significant differences in individual country rankings $(\mathrm{p}<0.05)$ compared to the base period until 2000, after that the process stabilized. Between 1992 and 2004, the countries in a lowest position like Portugal (+7), Austria and Greece (+6), improved their position the most and the biggest fall from the initially high position occurred in Finland (-8) and Denmark (-6).

Table 4: Sigma and Gamma Convergence in EU-15, 1992-2004

\begin{tabular}{|c|c|c|c|c|c|c|}
\hline & \multicolumn{3}{|c|}{ Total health expenditure, \% GDP } & \multicolumn{2}{c|}{ Total health expenditure, PPP\$ per capita } \\
\cline { 2 - 7 } & & $\begin{array}{c}\text { Multi-annual } \\
\text { Kendall }\end{array}$ & $\begin{array}{c}\text { Binary- } \\
\text { Kendall }\end{array}$ & 价onvergence & $\begin{array}{c}\text { Multi-annual } \\
\text { Kendall }\end{array}$ & Binary-Kendall \\
\cline { 2 - 7 } & $\boldsymbol{\sigma}$-convergence & 1.0000 & 1.0000 & 1.0000 & 1.0000 & 1.0000 \\
\hline 1992 & 1.0000 & 0.9857 & 0.9857 & 0.9757 & 0.9893 & 0.9893 \\
\hline 1993 & 0.9830 & 0.9857 & 0.9875 & 0.9509 & 0.9762 & 0.9750 \\
\hline 1994 & 1.0999 & 0.9585 & 0.9661 & 0.9902 & 0.9652 & 0.9643 \\
\hline 1995 & 1.1727 & 0.9300 & 0.9321 & 0.9836 & 0.9546 & 0.9429 \\
\hline 1997 & 1.1904 & 0.8482 & 0.7821 & 0.8994 & 0.9280 & 0.8875 \\
\hline 1998 & 1.1885 & 0.8118 & 0.7804 & 0.9085 & 0.9173 & 0.8875 \\
\hline 1999 & 1.2202 & 0.7915 & 0.7732 & 0.9213 & 0.9145 & 0.8893 \\
\hline 2000 & 1.2003 & 0.7797 & 0.7571 & 0.8793 & 0.9151 & 0.8911 \\
\hline 2001 & 1.2081 & 0.7766 & 0.7571 & 0.8558 & 0.9171 & 0.9054 \\
\hline 2002 & 1.0426 & 0.7740 & 0.7357 & 0.8931 & 0.9136 & 0.8732 \\
\hline 2003 & 0.9768 & 0.7754 & 0.7357 & 1.0929 & 0.9131 & 0.8696 \\
\hline 2004 & 0.8823 & 0.7812 & 0.7696 & 1.1517 & 0.9120 & 0.8679 \\
\hline$\Delta, \%$ & -1.04 & -2.04 & -2.16 & 1.18 & -0.76 & -1.17 \\
\hline
\end{tabular}

Table 4 also characterizes changes in health care expenditure (as PPP\$). In EU-15, $\sigma$-divergence has taken place, on average $1.18 \%$ per year. Together with growing differences, major changes in country rankings had taken place until 1997, and then the process stabilized. By multi- and binary methods, the speed of $\gamma$-convergence was $0.76 \%$ and $1.17 \%$ per year. The biggest changes compared to 1992 have been in Austria (+6) - forward, and in Sweden (- 6) - backward. 
Contrary to the EU-15 countries, a fast $\sigma$-convergence in health care expenditures as \% of GDP took place in EU-8 group in $1992-1999$ (Table 5). In 2000, the indicators started to diverge again. The average annual speed was $4.5 \%$. Parallel to $\sigma$-convergence, also $\gamma$-convergence took place, lasting until the last year of the test period.

Table 5: Sigma and Gamma Convergence in the EU- 8, 1992-2004

\begin{tabular}{|c|c|c|c|c|c|c|}
\hline & \multicolumn{3}{|c|}{ Total health expenditure, \% GDP } & \multicolumn{3}{|c|}{ Total health expenditure, PPP\$ per capita } \\
\hline & $\sigma$-convergence & $\begin{array}{c}\text { Multi-annual } \\
\text { Kendall }\end{array}$ & $\begin{array}{l}\text { Binary- } \\
\text { Kendall }\end{array}$ & $\sigma$-convergence & $\begin{array}{c}\text { Multi-annual } \\
\text { Kendall }\end{array}$ & $\begin{array}{l}\text { Binary- } \\
\text { Kendall }\end{array}$ \\
\hline 1992 & 1.0000 & 1.0000 & 1.0000 & 1.0000 & 1.0000 & 1.0000 \\
\hline 1993 & 0.8618 & 0.9405 & 0.9762 & 1.3626 & 0.9762 & 0.9762 \\
\hline 1994 & 0.8128 & 0.9259 & 1.0000 & 1.2777 & 0.9418 & 0.9286 \\
\hline 1995 & 0.7135 & 0.9286 & 0.9762 & 1.4178 & 0.9286 & 0.9048 \\
\hline 1996 & 0.5496 & 0.9352 & 0.9762 & 1.2923 & 0.9295 & 0.9048 \\
\hline 1997 & 0.5154 & 0.9153 & 0.9405 & 1.2509 & 0.9339 & 0.9048 \\
\hline 1998 & 0.5920 & 0.8989 & 0.9405 & 1.0434 & 0.9388 & 0.9048 \\
\hline 1999 & 0.4298 & 0.9010 & 0.9762 & 1.0121 & 0.9435 & 0.9048 \\
\hline 2000 & 0.5561 & 0.8889 & 0.9048 & 1.0788 & 0.9477 & 0.9048 \\
\hline 2001 & 0.6227 & 0.8733 & 0.8690 & 1.0386 & 0.9467 & 0.8810 \\
\hline 2002 & 0.7105 & 0.8650 & 0.8690 & 1.0135 & 0.9425 & 0.8571 \\
\hline 2003 & 0.7169 & 0.8677 & 0.9048 & 0.9570 & 0.9464 & 0.9048 \\
\hline 2004 & 0.5703 & 0.8518 & 0.8333 & 0.8451 & 0.9467 & 0.8810 \\
\hline$\Delta, \%$ & -4.572 & -1.328 & -1.508 & -1.39 & -0.46 & -1.05 \\
\hline
\end{tabular}

In EU-8 countries (PPP\$ per capita), the country differences had decreased by 2004, compared to 1992 (Table 5), despite the divergence at the beginning of the test period when the variation coefficient increased by $12 \%$ a year. The Kendall's index declined at the beginning of the test period, indicating changes in the country ranking. Hungary, which initially was in the leading position, declined to the third position and Slovenia occupied the leading position in 1995 and has retained it among EU-8 countries until today. But changes in the country rankings were not statistically significant $(\mathrm{p}<0.05)$. In the following years, $\sigma$ declined until 1998-1999 and stabilized after that. Changes in the period 2002-2004 changed $\sigma<1$, and the average annual speed of the whole period was $1.39 \%$. Kendall's indexes were more or less stable, indicating absence of $\gamma$-convergence. The highest indicator was in Slovenia and Czech Republic, the lowest in Latvia and Lithuania. Estonia has remained on the sixth-seventh position throughout the test period. From the non-existence of $\gamma$ we can conclude that $\beta$-convergence occurred only in 1996-2004 (an exception was 2000), together with $\sigma$-convergence.

Computing the $\sigma$ index analogously with the variation coefficient, but using EU-15 average instead of EU-8 average, we get an indicator that describes changes in EU-8 compared to EU-15 average. During the whole period, differences have declined, on average $1.33 \%$ per year. According to this calculation, the convergence of EU-8 to the level of EU-15 would take approximately 23 years.

Analyzing all EU-23 members together (Table 6), we can perceive $\sigma$-convergence during the whole period (total health expenditure, PPP\$ per capita) - on average $0.90 \%$ per year and as \% of GDP - 2.34 per year. Consequently, the $\beta$-convergence has also taken place. Kendall's indicators remained stable, changing on average $0.2-0.3 \%$ per year. During the convergence period (PPP\$ per capita) there were very few changes in country ratings. Not one new member could surpass any EU-15 country and changes in the rankings took place only within country groups. 
Table 6: Sigma and Gamma Convergence in the EU- 23, 1992-2004

\begin{tabular}{|c|c|c|c|c|c|c|}
\hline & \multicolumn{3}{|c|}{ Total health expenditure, \% GDP } & \multicolumn{3}{|c|}{ Total health expenditure, PPP\$ per capita } \\
\hline & $\sigma$-convergence & $\begin{array}{c}\text { Multi-annual } \\
\text { Kendall }\end{array}$ & $\begin{array}{l}\text { Binary- } \\
\text { Kendall }\end{array}$ & $\sigma$-convergence & $\begin{array}{c}\text { Multi-annual } \\
\text { Kendall }\end{array}$ & $\begin{array}{l}\text { Binary- } \\
\text { Kendall }\end{array}$ \\
\hline 1992 & 1.0000 & 1.0000 & 1.0000 & 1.0000 & 1.0000 & 1.0000 \\
\hline 1993 & 0.9054 & 0.9827 & 0.9827 & 0.9984 & 0.9931 & 0.9931 \\
\hline 1994 & 0.8555 & 0.9583 & 0.9491 & 0.9593 & 0.9910 & 0.9891 \\
\hline 1995 & 0.8900 & 0.9211 & 0.8918 & 0.9697 & 0.9836 & 0.9743 \\
\hline 1996 & 0.8322 & 0.9122 & 0.8943 & 0.9436 & 0.9822 & 0.9743 \\
\hline 1997 & 0.8056 & 0.9087 & 0.8809 & 0.9275 & 0.9826 & 0.9753 \\
\hline 1998 & 0.8267 & 0.9083 & 0.8720 & 0.8993 & 0.9836 & 0.9758 \\
\hline 1999 & 0.7785 & 0.9111 & 0.8725 & 0.8994 & 0.9843 & 0.9783 \\
\hline 2000 & 0.8452 & 0.9114 & 0.8631 & 0.8959 & 0.9833 & 0.9718 \\
\hline 2001 & 0.8615 & 0.9124 & 0.8622 & 0.8909 & 0.9831 & 0.9718 \\
\hline 2002 & 0.8458 & 0.9144 & 0.8701 & 0.8702 & 0.9825 & 0.9718 \\
\hline 2003 & 0.8398 & 0.9149 & 0.8710 & 0.9073 & 0.9795 & 0.9654 \\
\hline 2004 & 0.7525 & 0.9151 & 0.8725 & 0.8973 & 0.9777 & 0.9639 \\
\hline$\Delta, \%$ & -2.34 & -0.74 & -1.13 & -0.90 & -0.19 & -0.31 \\
\hline
\end{tabular}

Based on the $\sigma$-convergence index that was calculated on the basis of EU-15 average, the EU-8 differences declined until 1994, after that the process stabilized and since 1999 a divergence can be seen. The same trend can be perceived while analyzing EU-23 together. Both $\sigma$ - and $\gamma$-convergence took place until 1994 and after a stabilization period, the differences increased again.

\section{CONCLUSIONS}

In this paper we examined the convergence of health care expenditure in EU countries. For testing $\beta-, \sigma$ and $\gamma$-convergence we used cross-sectional data over the period 1992-2004 for health care expenditure as share of GDP and per capita. The results of the analysis indicate that there has been $\beta$-convergence in health care expenditure as a share of GDP. The rate of convergence shows a rather high speed of convergence: starting from 1992, it takes about 10 years for one half of the differences in health care expenditure (as a share in GDP) between EU-8 countries and EU-15 average to disappear at the 7\% annual rate of convergence.

The test for $\sigma$-convergence in EU-23 countries, independently in EU-15 and EU-8 countries, confirmed that the health care expenditures have converged in the period 1992-2004. The annual average speed of $\sigma$-convergence was $1.04 \%$ and the average speed of $\gamma$-convergence, based on Kendall's binary and multi-annual indices, was $2.04 \%$ and $2.16 \%$ in EU-15. There were statistically significant differences in individual country rankings compared to the base period until 2000, after that the process stabilized (between 1992 and 2004, the countries in the lowest position like Portugal, Austria and Greece, improved their position the most and the biggest fall from the initially high position occurred in Finland and Denmark). In EU-8 group the average annual speed of convergence was 4.5\%. For all EU-23 countries, we can perceive $\sigma$-convergence during the whole period by an average of $0.90 \%$ annually; $\beta$ convergence has also taken place and Kendall's indicators remained stable, changing on average by $0.2-0.3 \%$ per year (there were very few changes in country ratings, not one EU-10 member state could surpass any EU-15 country and changes in the rankings took place only within country groups).

\section{REFERENCES}

1. Alsan, M, Bloom D.E., Canning, D. (2006). The effect of population health on foreign direct investment inflows to low- and middle-income countries. World Development, No. 34(4), pp.613-630

2. Barro, R. J. (1991) Economic Growth in a Cross Section of Countries. Quarterly Journal of Economics, No. 2, pp. 407-443.

3. Barro, R. and Sala-i-Martin, X. 1991. Convergence across States and Regions. Brookings Papers on Economic Activity, 1, 107-182. 
4. Barro, R. J., Sala-i-Martin, X. (1992) Convergence. Journal of Political Economy No. 110, pp. $223-252$.

5. Bils, M., Klenow, P. J. (2000) Does Schooling Cause Growth. The American Economic Review, No. 90, pp. 1160-1184.

6. Bhargava, A., Jamison, D., Lau, L. J., Murray, C.J.L. (2001) Modeling the effects of health on economic growth. Journal of Health Economics, No. 20, pp. 423-440.

7. Bloom, D. E., Canning, D., Graham B. (2003). Longevity and life cycle savings. Scandinavian Journal of Economics, No. 105, pp. 423-440.

8. Bloom, D.E., Canning, D., Sevilla, J. (2001) The Effect of Health on Economic Growth: Theory and Evidence. NBER Working Paper, No. 8587.

9. Brainerd, E., Kawachi I., Kennedy, B. (1998) The Role of Social Capital in the Russian Mortality Crisis. World Development, 11, pp. 2029-2043.

10. Boyle, G. E., McCarthy, T.G. (1997) A Simple Measure of $\beta$-Convergence. Oxford Bulletin Economics and Statistics, 59, 2, pp.257-264.

11. Boyle, G.E., McCarthy, T.G. (1999) Simple Measure of Convergence in per capita GDP: a Note on some Further International Evidence. National University of Ireland, Maynooth, Co.Kildare.

12. Campos, F. N., Coricelli, F. (2002) Growth in Transition: What We Know, What We Don't, and What We Should. Journal of Economic Literature, No.3, pp. 793-836.

13. Cohen, D. (1996) Tests of the Convergence Hypothesis: Some Further Results. Journal of Economic Growth, No. 3, pp. 351-361.

14. DeLong, B.J. (1998) Productivity Growth, Convergence, and Welfare: Comment. American Economic Review, No 5, pp. 1138-1154.

15. Dorwick, S., Nguyen D. (1989), OECD Comparative Economic Growth 1950-85: Catch-Up and Convergence, American Economic Review, Vol. 79 (5), pp. 1010-1030.

16. Jamison D., Lau, L., Wang J. (2004). Health's contribution to economic growth in an environment of partially endogenous technical progress. Disease control priorities project U.S. National Institutes of Health. Working Paper No. 10. http://www.dcp2.org

17. Kalemi-Ozcan S., Ryder H. E., Weil D. N. (2000). Mortality decline, human capital investment, and economic growth. Journal of Development Economics, No. 62(1), pp. 1-23.

18. Macroeconomics and Health: Investing in Health for Economic Development (2001). Report of the Commission on Macroeconomics and Health. WHO, Geneva.

19. Mankiw G. N., Romer D., Weil D. N. (1992) A Contribution to the Empirics of Economic Growth. Quarterly Journal of Economics, No. 2, pp. 407-437.

20. Nixon, J. (1999) Convergence Analysis of Health Care Expenditure in the EU Countries Using Two Approaches. Discussion Papers in Economics, No.3, University of York.

21. O’Neill, D. (1995). Education and Income Growth: Implications for Cross-Country In equality. Journal of Political Economy, No 6, pp. 1289-1301.

22. Püss T., Viies, M., Maldre, R. (2003) Convergence Analysis in Social Protection Expenditure in the European Union. In: Ülo Ennuste and Lisa Wilder (eds.). Essays in Estonian Transformation Economics. Estonian Institute of Economics at TTU, pp. 123-148.

23. Quah, D. (1996). Twin Peaks: Growth and Convergence in Models of Distribution Dynamics. - The Economic Journal, 106, 437, 1045-1055.

24. Sab R., Smith S. (2001) Human Capital Convergence: International Evidence. IMF Working Paper 32, p. 33.

25. Sala-i-Martin, X. (1994), Regional Cohesion: Evidence and Theories of Regional Growth and Convergence, Discussion Paper No. 1075, Centre for Economic Policy Research.

26. Sala-i-Martin, X. (1996) The Classical Approach to Convergence Analysis. Economic Journal, No. 106, pp. 1019-1036.

27. Sala-i-Martin, X., Doppelhofer G., Miller R I. (2004). Determinants of long-run growth: a Bayesin averaging of classical estimates (BACE) approach. American Economic Review, No. 94(4), pp.813-835.

28. WHO European health for all database. http://data.euro.who.int/hfadb/ 
NOTES 